\title{
Temas Fundamentais em Avaliação Psicológica
}

\author{
Hutz, C. S., Bandeira, D. R., \& Trentini, C. M. (Ed.) (2015). Psicometria. Porto Alegre: Artmed.
}

Esta resenha propõe-se a apresentar o livro "Psicometria", publicado em 2015, sob organização dos professores e pesquisadores da Universidade Federal do Rio Grande do Sul, Claudio S. Hutz, Denise R. Bandeira e Clarissa M. Trentini. O livro refere-se ao primeiro título de uma coleção de três livros, denominada "Avaliação Psicológica". Além do livro, tema desta resenha (Psicometria), os demais títulos componentes da coleção são "Psicodiagnóstico" e "Avaliação da Inteligência e da Personalidade", os quais deverão ser publicados nos próximos meses.

O livro Psicometria é composto por 192 páginas, divididas entre 11 capítulos, que versam sobre temas centrais em Psicometria e Avaliação Psicológica e envolvem os processos de aplicação, construção, adaptação, validação e normatização a que os instrumentos psicológicos, no Brasil, devem apresentar para seu reconhecimento junto ao Sistema de Avaliação dos Testes Psicológicos (SATEPSI), habilitando-o ao uso profissional do psicólogo em território nacional. Também são abordadas questões de ética profissional no âmbito da avaliação psicológica. Vale destacar que, ao final de cada capítulo, são propostas questões de revisão do conteúdo abordado.

Intitulado "O que é avaliação psicológica- métodos, técnicas e testes", o primeiro capítulo foi escrito por Claudio Simon Hutz e apresenta diferenças entre a definição de teste psicológico e avaliação psicológica, aborda ainda questões fundamentais da psicometria, como norma, ponto de corte, desvio padrão. $\mathrm{O}$ autor também aponta outros métodos para auxiliar o processo de avaliação psicológica, quais sejam, a entrevista e a observação.

O segundo capítulo foi escrito por Nelson Hauck Filho e Cristian Zanon e intitula-se "Questões básicas sobre mensuração". Nesse capítulo, os autores tratam da importância e relevância da mensuração de fenômenos psicológicos e também apresentam quatro formas para a mensuração desses fenômenos, a saber, a Teoria Clássica dos Testes (TCT), as Escalas de Medida, a Teoria da Medida Conjunta e, também, os modelos de Variáveis Latentes. Para cada uma das quatro formas mencionadas, os autores destacam os conceitos principais, suas vantagens e desvantagens.
Nessa mesma direção, o capítulo três foi escrito por Juliana Cerentini Pacico e intitula-se "Normas". A autora apresenta o conceito de "norma" e atenta para a importância do processo de interpretação dos escores dos testes, ressaltando conceitos, como amostra normativa, tamanho da amostra, normas intragrupo, escore bruto, percentil, escore padrão. Igualmente são abordadas exigências nesse âmbito para que o Conselho Federal de Psicologia (CFP) possa emitir parecer favorável ao instrumento desenvolvido ou adaptado com amostras populacionais nacionais. Além das normas voltadas para grupos, a autora apresenta fontes de normas associadas ao desenvolvimento humano, como idade, série escolar e estágio do desenvolvimento.

Com mesma autoria do anterior, o capítulo quatro chama-se "Como é feito um teste? Produção de itens". O capítulo aborda as etapas para a construção de instrumentos psicológicos objetivos e de qualidade. Inicialmente, a autora discute as diferenças, vantagens e desvantagens entre construir ou adaptar um instrumento. A respeito da construção de instrumentos, foram destacados procedimentos, como a revisão da literatura, a definição operacional, a elaboração dos itens do instrumento, alguns cuidados (critérios) nesse âmbito, assim como a etapa de análise de juízes. No que se refere à adaptação de instrumentos, a autora aponta diretrizes propostas pela International Test Commission (ITC), as quais baseiam as orientações do SATEPSI nesse mesmo âmbito.

Após a etapa de construção ou tradução dos itens do instrumento, deve-se sujeitar os itens construídos a procedimentos que irão buscar evidências de validade à medida que se está construindo ou adaptando, com o objetivo de verificar se o conjunto de itens mede o fenômeno que se propõe. No capítulo cinco, chamado "Validade", Juliana C. Pacico e Claudio S. Hutz apresentam e discutem as evidências de validade de conteúdo, de critério (convergente e discriminante) e baseada na estrutura interna (de construto). Os autores propõem que os pesquisadores se preocupem em buscar diferentes fontes de evidências de validade às medidas psicológicas em construção.

O capítulo sexto, intitulado "Fidedignidade", foi elaborado por Cristian Zanon e Nelson Hauck Filho e aborda a conceituação e a importância dos estudos 
de precisão das medidas psicológicas. A fidedignidade é citada como uma propriedade psicométrica fundamental para a validade dos testes, a qual está diretamente relacionada com o erro de medida. Igualmente, os autores apresentam procedimentos para estimar a precisão da medida, a saber, teste-reteste, formas alternadas, duas metades, coeficiente de alfa $(\alpha)$ e ainda o método de fidedignidade do avaliador (associado às medidas projetivas). Limitações dos métodos clássicos de avaliação da fidedignidade encerram o capítulo.

Considerando as limitações apresentadas no capítulo anterior e com o objetivo de complementar os métodos clássicos de análise de itens e de escalas, o capítulo sete, intitulado "Análise de itens e Teoria de resposta ao item" foi escrito por Tatiana C. Nakano. Ricardo Primi e Carlos H. S. S. Nunes e apresenta o modelo da Teoria da resposta ao item (TRI), no qual, cada elemento do teste, é avaliado individualmente, diferente do que ocorre no modelo clássico (TCT), que prioriza o teste por inteiro. Os autores citam vantagens da TRI em relação à TCT e também são discutidos conceitos básicos do modelo, associados às curvas características dos itens, mapa de itens e também a análise do funcionamento diferencial dos itens (DIF).

O capítulo oito denomina-se "Análise de rede aplicada à psicometria e à avaliação psicológica" e foi elaborado por Wagner de Lara Machado, João Vissoci e Sacha Epskamp. Além de apresentar a análise de redes, são discutidas possíveis implicações na psicometria e na avaliação psicológica. Nesse sentido, são apresentados modelos de análises e comandos que podem ser reproduzidos por meio do software R. Os autores entendem que as redes fornecem características dos itens semelhantes às obtidas por outros métodos de análise. $\mathrm{O}$ capítulo encerra-se com indicações de impactos da análise de redes na psicometria e na avaliação psicológica.

O nono capítulo, escrito por Caroline Tozzi Reppold e Léia G. Gurgel, intitula-se "O papel do teste na avaliação psicológica”. O capítulo aborda mais amplamente a conceituação, a importância e as etapas do processo de avaliação psicológica, apresentando a representação e a contribuição dos instrumentos psicológicos nesse processo. As autoras comentam a realidade dos testes no Brasil, perpassando pelo aumento no interesse de pesquisadores e por psicólogos atuantes (por exemplo, na clínica, na educação), culminando na criação do SATEPSI e na regulamentação dos procedimentos e instrumentos necessários à avaliação psicológica. Também são apontados cuidados necessários na escolha dos testes e no processo de aplicação, assim como na utilização de outras técnicas possíveis de avaliação psicológica.

Nessa mesma direção, o décimo capítulo retoma questões éticas envolvendo o processo de avaliação psicológica, tendo sido elaborado por Claudio Simon Hutz. Intitulado "Questões éticas na avaliação psicológica”, o capítulo inicia atentando para a importância do processo de avaliação psicológica e do resultado decorrente dela, o que torna o psicólogo um profissional com extrema responsabilidade e, portanto, com o dever de conhecer e respeitar seu código de ética. Isso inclui a qualificação dos profissionais em relação aos instrumentos desenvolvidos. $\mathrm{O}$ autor também apresenta três princípios para orientar a realização de avaliações psicológicas, sendo eles, o respeito pelas pessoas, a beneficência e a justiça, os quais devem ser atentados, com o fim de garantir a dignidade, a igualdade e a integridade dos seres humanos, pontuados no código de ética profissional do psicólogo.

O ultimo capítulo denomina-se "Testes psicológicos disponíveis no Brasil - O SATEPSI" e foi escrito por Caroline T. Reppold e Léia G. Gurgel. Nesse capítulo, as autoras descrevem a criação do Sistema de Avaliação dos Testes Psicológicos (SATEPSI), objetivando qualificar os instrumentos psicológicos brasileiros e também aprimorar a construção e validação desses instrumentos, a partir de parâmetros científicos. Dessa forma, para as autoras, a construção do SATEPSI representa um avanço na área da avaliação psicológica, à medida que permite que profissionais consultem os instrumentos com parecer favorável e desfavorável, disponibilizados por meio do site do SATEPSI. Adicionalmente, as autoras abordam aspectos técnicos do SATEPSI e encerram o capítulo discutindo brevemente a questão dos instrumentos com parecer desfavorável para uso no Brasil.

Após a apresentação do livro Psicometria, faz-se possível destacar que são apresentados conceitos e discussões técnicas e éticas fundamentais que englobam os testes psicológicos e a avaliação psicológica. Dessa forma, o livro se caracteriza como uma rica fonte de informações para graduandos em Psicologia, alunos de cursos de especialização em Avaliação Psicológica, assim como pesquisadores interessados na área. Igualmente, o livro poderá contribuir com o psicólogo que utiliza avaliação psicológica, à medida que discute e informa o leitor a respeito de questões técnicas e éticas que envolvem a prática profissional.

Recebido: 17/07/2015

Primeira reformulação: 23/09/2015

Aprovado: 24/09/2015

Psico-USF, Bragança Paulista, v. 20, n. 3, p. 561-563, set./dez. 2015 
Sobre o autor:

Jeferson Pires é psicólogo e aluno do Programa de Pós-Graduação em Psicologia da Universidade Federal de Santa Catarina, na linha de Avaliação em Saúde e Desenvolvimento, em nível de Mestrado. Atualmente integra o Laboratório de Pesquisa em Avaliação Psicológica e o Laboratório de Educação Cerebral, ambos na UFSC.

E-mail: jefersongp@gmail.com

Contato com o autor:

Universidade Federal de Santa Catarina

Centro de Filosofia e Ciências Humanas, Departamento de Psicologia

Trindade - 88040-970 - Florianópolis, SC - Brasil

E-mail: jefersongp@gmail.com

Psico-USF, Bragança Paulista, v. 20, n. 3, p. 561-563, set./dez. 2015 
